\title{
Structure Breakdown of Stirred Yoghurt in a Circular Pipe as Affected by Casein
}

\section{and Fat Content}

\author{
Basim ABU-JDAYIL $^{1^{*}}$, M.S. NASSER ${ }^{2}$ and Mamdouh GHANNAM ${ }^{1}$ \\ ${ }^{1}$ Chemical \& Petroleum Engineering Department, U.A.E. University, Al-Ain, P.O. Box: 17555, U.A.E. \\ ${ }^{2}$ Department of Chemical \& Petrochemcial Engineering,University of Nizwa, PO Box 33 Postal Code 616 Birkat Al Mawz; Sultanate of \\ Oman
}

Received Octobr 1, 2012; Accepted December 11, 2012

In this study, the rheological and flow properties of stirred yoghurt in a circular pipe as affected by casein and fat content were investigated. The structure breakdown of the stirred yoghurt was evaluated from the rheological measurements and compared with that estimated from pipe flow data through estimating the dimensionless structure number $(\mathrm{Se})$ and Deborah number $(\mathrm{De})$. The rheological tests revealed that increasing the casein and fat content led to increase the apparent viscosity of the stirred yoghurt and its dependence on shearing time. Both, the rheological and pipe flow tests revealed that the thixotropic behaviour of stirred yoghurt increased with casein and fat content, where the rate of structure breakdown of yoghurt in pipe flow was greater than the build-up rate. On the other hand, increasing the casein and fat content in stirred yoghurt resulted in an increase in the Deborah number $(D e)$, which means an increase in the elasticity of the yoghurt. It was shown in this work that the simple rheological tests can be used to estimate the structure breakdown rate of stirred yoghurt in pipe flow.

Keywords: stirred yoghurt, circular pipe flow, rheology, fat, casein

\section{Introduction}

Yoghurt is usually classified in two basic types, according to its physical state in the retail container: set yoghurt and stirred yoghurt (Afonso and Maia, 1999). Set yoghurt is fermented then consumed without further treatment while stirred yoghurt is fermented in large tanks, stirred and subsequently packed (Sodini et al., Remeuf et al., 2004; Lee and Lucey, 2004; Damin et al., 2009). In set yogurt, fermentation takes place after pouring the milk with starter culture in the containers. Yogurt is set in the containers and has a thick consistency and a thin flat skin on the top. The stirred yoghurt should have a smooth texture with high viscosity. The product becomes smoother if the stirring is more intense, but the intense stirring also lowers the viscosity.

Much effort has been invested into the optimizing structure breakdown of the stirred yoghurt. In all processes, the yoghurt gel is firstly broken by stirring in the tank. The second structuring step varies greatly, which partly depends

*To whom correspondence should be addressed.

E-mail: Babujdayil@uaeu.ac.ae on product composition. One extreme is the use of a colloid mill to smoothen the high-solids yoghurt. On the other hand, pumping the product through some type of restriction like homogenizer valves and sieves is used for less viscous products.

Yoghurt exhibits a complex rheology that depends on many factors such as the temperature and the milk composition (Fangary et al., 1999). The understanding of the rheological properties of yoghurt is important to texture, stability, and process design. Therefore, many researchers used rheological techniques as a tool to study the structure breakdown of yoghurt (Aportela-Palacios et al., 2005; Damin et al., 2008; Xu et al., 2008; Akalin et al., 2008; Renan et al., 2009; McCann et al., 2011). In the literature, most of researchers considered either the stirred yoghurt processing parameters (Kemblowski and Petera, 1981; Benzech and Maingonnat, 1993; Mullineux and Simmonsor, 2008) or their rheological behaviour (Jumah et al., 2001; Shaker et al., 2002; Mohameed et al., 2004; Ciron et al., 2011; Ciron, et al., 2012) without attempting to relate them. Evidently it is important to search for links between the properties of yoghurt during processing with the 
rheological behaviour of the final product.

On the other hand, variations in the rheological properties of stirred yoghurt have been attributed to several factors. These can be of a physical nature such as those related with milk composition and type of starter culture, or processing conditions-related, such as homogenization, thermal pretreatment of the milk and post-incubation stages that include stirring, pumping, cooling and packaging (Afonso and Maia, 1999). The physical state of fats and proteins present in the milk is one of the physical nature factors that have a big influence of the texture and flow behaviour of stirred yoghurt (Fangary et al., 1999).

Casein is a group name for the dominant class of proteins in the milk. The casein easily forms aggregates containing identical or different types of molecules (Gost, 1995). In the yoghurt structures, the casein is the main component involved in the gels made from milk by acidification. In addition, the preparation of yoghurt from homogenized milk coats the increased surface of fat globules with casein, enabling the fat globules to participate as a copolymer with casein to strengthen the gel network (Everett and McLeod, 2005).

Puvanenthiran, Williams and Augustin (2002) found in their study on set yoghurt that as the casein $(\mathrm{CN})$ to whey protein (WP) ratio was decreased the maximum gel strength of the yoghurt increased. Scanning electron microscopy indicated that gels with a lower proportion of casein had a finer structure with numerous small pores and a dense network of crosslinks (Puvanenthiran et al., 2002). Similar results have been reported by Kücükcetin (2008) that as CN to WP ratio increased in the stirred yogurt the number of grains, perimeter of grains, visual roughness, storage modulus and yield stress decreased.

In a recent study of Krzeminski et al. (2011), the effect of whey protein addition on structural properties of stirred yoghurt systems at different protein and fat content was studied. It was observed that the relative magnitude of the texturizing and stabilizing effect depended on the presence of whey protein concentration and the presence of fat globules, and thus on type and strength of interparticle interactions. As whey protein content raised, the particle size, viscosity, and network firmness also increased.

In this study an attempt was made to correlate the rheological behaviour and the flow properties through a circular pipe for stirred yoghurt, in order to predict the structure behaviour of stirred yoghurt from simple rheological test. This approach was demonstrated by changing the casein and fat content of stirred yoghurt. This method enables one to achieve the ease and optimal production that will be reflected in the quality of the final product.

\section{Theoretical Analysis}

The relationships between the structure number $(\mathrm{Se})$, Deborah number $(D e)$, and Reynolds number $(R e)$ describing the flow behaviour of yoghurt in a circular pipe flow and the rheological parameters like the shear stress and shear rate that can be obtained from the classical rheological test using a rotational viscometer have been demonstrated by using yoghurts with different casein and fat content.

Deborah number incorporates both on the elasticity and viscosity of the material. The smaller $D e$, the material behaves more fluid like with an associated Newtonian viscous flow. At higher De, the material behavior changes to non-Newtonian regime, increasingly dominated by elasticity, reaching solid like behavior with very high Deborah numbers. In addition, Deborah number can be quantified as the ratio of the characteristic time of the material to the characteristic time of the process. The characteristic time of a material may be considered as an order of magnitude estimate for how long it takes the substance to complete a stress relaxation process (Pipkin, 1986). If a material is an ideal solid, the characteristic time is infinity and no relaxation occurs. On the other hand, the characteristic time of an ideal viscous material is zero meaning relaxation is immediately (Steffe, 1996). For example, the characteristic time of water is $10^{-12} \mathrm{~s}$, and the characteristic time for glass (a super cooled liquid at room temperature) is greater than $10^{5} \mathrm{~s}$. Hence, the elastic effects of water are difficult to observe when it is deformed, because it relaxes very quickly. On the other hand, the viscous behaviour of glass is not easily observed because the response to the deforming force (gravity) on a vertical pane is very slow; therefore, decades are needed to observe a change in the material (Steffe, 1996).

The structure number $(\mathrm{Se})$ characterizes the state of the material at the pipe entrance. If $S e=1$, then the fluid structure at the pipe entrance is equal to the mean value of the equilibrium structure in a cross-section very far from this pipe entrance. While the other cases, $\mathrm{Se}>1$ and $\mathrm{Se}<1$ describe a breakdown and build-up respectively of the structure of the material in the pipe (Kemblowski and Petera, 1981).

One of the important concepts to characterize the flow of fluid is by means of Reynolds number $(R e)$, which takes into consideration the nature of the fluid through its viscosity and density, the flow conditions by the fluid velocity, and the system geometry by considering the diameter of the pipe (Rao, 2010 ). The Reynolds number is the ratio of the kinetic force to the viscous force of the fluid flow. For example, if the viscosity of the fluid is high, $R e$ will be low and the flow will be stabilized. While if the velocity is high, Re will be high and the flow will be disturbed. In pipe flow the following values of $R e$ can be used to characterize the flow: if $R e<2100$, the 
flow is laminar; if $R e>4000$, the flow is turbulent; and if $R e$ is in between 2100 and 4000, the flow is transient (Rao, 2010).

The rheological state equation describing shear stress for non-Newtonian thixotropic fluid like yoghurt is:

$$
\tau(t, \dot{\gamma})=\lambda(t, \dot{\gamma}) \cdot \tau_{i}(\dot{\gamma})=\lambda(t, \dot{\gamma}) \cdot k_{i} \dot{\gamma}^{n_{i}}
$$

and the structural parameter decay equation:

$$
\begin{aligned}
& \frac{d \lambda}{d t}=-C\left[\lambda(t, \dot{\gamma})-\lambda_{e}\right]^{p} \quad \text { when } \lambda>\lambda_{e} \\
& \frac{d \lambda}{d t}=0.0 \quad \text { when } \lambda \leq \lambda_{e}
\end{aligned}
$$

where $\tau$ is the shear stress, $\dot{\gamma}$ is the shear rate, $n$ is the flow behavior index, $k$ is the consistency coefficient, $\lambda$ is the structural parameter, $C$ is the rate of structural decay (the speed of structure breakdown), $p$ is the order of the structure breakdown, and $\lambda_{e}$ is the equilibrium state.

For a shear thinning material follows the power law model like yoghurt (Benezech and Maingonnat 1993; Abu-Jdayil et al., 2000; Abu-Jdayil, 2003; Aportela-Palacios et al., 2005; Renan et al., 2009), and by taking the order of the structure breakdown " $p$ " equals two for stirred yoghurt (Benzech and Maingonnat, 1993), then the structural decay parameter, $\lambda$, can be given by:

$$
\lambda=\lambda_{e}+\left[\frac{1}{\lambda_{i}-\lambda_{e}}+C . t\right]^{-1}
$$

This also leads to $\lambda_{i}=1$ (complete structure) and $\lambda_{e}=\frac{\tau_{e}(\dot{\gamma})}{k_{i} \dot{\gamma}^{n_{i}}}=\frac{\tau_{e}}{\tau_{i}}$, where $\lambda_{e}$ and $C$ are assumed to be constants and independent of shear rate for stirred yoghurt (Schmitt et al., 1998).

The dimensionless structure number $(\mathrm{Se})$ which is defined as the ratio of the axial pressure gradients at the pipe entrance $\left(-\frac{\partial P}{\partial x}\right)_{i}$ to the axial pressure gradient at the pipe exit as $x \rightarrow \infty,\left(-\frac{\partial P}{\partial x}\right)_{e}$ where rheological equilibrium of the fluid occurs, can be written as (Schmitt et al., 1998):

$$
S e=\frac{\left(-\frac{\partial P}{\partial x}\right)_{i}}{\left(-\frac{\partial P}{\partial x}\right)_{e}}=\left[\frac{\left(\frac{3 n_{i}+1}{4 n_{i}}\right)^{n_{i}}}{\left(\frac{3 n_{e}+1}{4 n_{e}}\right)^{n_{e}}}\left(\frac{8 V_{m}}{D}\right)^{n_{i}-n_{m e}}\right] \cdot \frac{k_{i}}{k_{e}}
$$

where $\left(\frac{8 V_{m}}{D}\right)$ is the wall shear rate.

On the other hand, the modified Deborah Number $(D e)$ is defined as (Kemblowski and Petera, 1981):

$$
D e=\frac{\left(3 n_{i}+1\right) \cdot V_{m}}{C . L .\left(n_{i}+1\right) \cdot\left(1-\lambda_{e}\right)}
$$

While the Re number in a circular pipe flow can be defined as (Schmitt et al., 1998):

$$
\operatorname{Re}=\left[\frac{4 n_{e}}{\left(3 n_{e}+1\right)}\right]^{n_{e}} \cdot \frac{V_{m}^{\left(2-n_{e}\right)} \cdot D^{n_{e}} \cdot \rho}{8^{\left(n_{e}-1\right)} \cdot k_{e}}
$$

To evaluate the $S e, D e$ and $R e$ numbers for a yoghurt flow in pipes, it was necessary to determine the rheological parameters $n_{i}, n_{e}, k_{i}, k_{e}, \lambda_{e}$ and $C$. The systematic procedure to estimate these rheological parameters was as follows: By using a rheometer, the shear stress versus time was measured for five different shear rates. Then from these measurements $\tau_{i}$ and $\tau_{e}$ for each shear rate was estimated. By fitting the data to the power-law model, $n_{i}, k_{i}, n_{e}$ and $k_{e}$ were determined.. In addition $C$ and $\lambda_{e}$ were evaluated from the plot of $\lambda$ versus time of shearing (see equation 4). By using the above rheological parameters, $S e, D e$ and Re numbers were calculated, which are needed to estimate the friction in a circular pipe. On the other hand the Se number was also calculated from the pressure drop measurements along the circular pipe.

\section{Materials and Methods}

Preparation of stirred yoghurt Different casein and fat content milks are provide by Dairy Crest, U.K. Yoghurt cultures mainly consist of a mixture of strains of lactic acid bacteria lactobacillus bulgaricus and streptococcus thermophilus. Ropy strains of lactic acid bacteria (RR) are often used to produce stirred yoghurt. In this study, two strains of pure commercial cultures for direct inoculation of the processed milk were used for the manufacture of yoghurt products, namely; RR (ropy) and ISt (moderate ropy) (obtained from CSK, Leeuwarden, The Netherlands). The pasteurized milk (5 min at $85^{\circ} \mathrm{C}$ having $0.05 \%(\mathrm{w} / \mathrm{w})$ fat, and $4.0 \%(\mathrm{w} / \mathrm{w})$ casein was inoculated using 0.03 g. $\mathrm{L}^{-1}$ mixtures of RR (ropy) and ISt (moderate ropy) in a ratio of $1: 1$. The inoculated milk was kept in a vessel for about $16-18 \mathrm{~h}$ at $42^{\circ} \mathrm{C}$ until $\mathrm{pH} 4.0$ \pm 0.2 was reached. To make stirred yoghurt the gels were gently stirred in a standardized way.

Circular pipe set up Figure 1 show the experimental setup used in this study. The vessel was filled by stirred yoghurt (after manually stirring) and a piston pump was used to pump the stirred yoghurt through a $10 \mathrm{~m}$ circular pipe having a diameter of $22 \mathrm{~mm}$. Stirred yoghurt with different casein $(4.0,4.4$, and $5.6 \%(\mathrm{w} / \mathrm{w})$ and different fat $(0.05,1.0,3.0$ and $8.0 \%(\mathrm{w} / \mathrm{w}))$ content were pumped through the circular pipe with a flow rate equal to $3.6 \mathrm{~L} / \mathrm{min}$ at $20^{\circ} \mathrm{C}$. For rheological characterization, the samples were collected from the sampling valve, and four pressure gauges were used to measure the pressure drop of the fluid (see Figure 1). The distance between the pump outlet and sampling valve is $2 \mathrm{~m}$. The 2 $\mathrm{m}$ zone is necessary to minimize the entrance effect and to reach the steady state flow conditions. Sampling was made carefully and with assuming that it altered as little as possible the viscosity of the product as little as possible. 


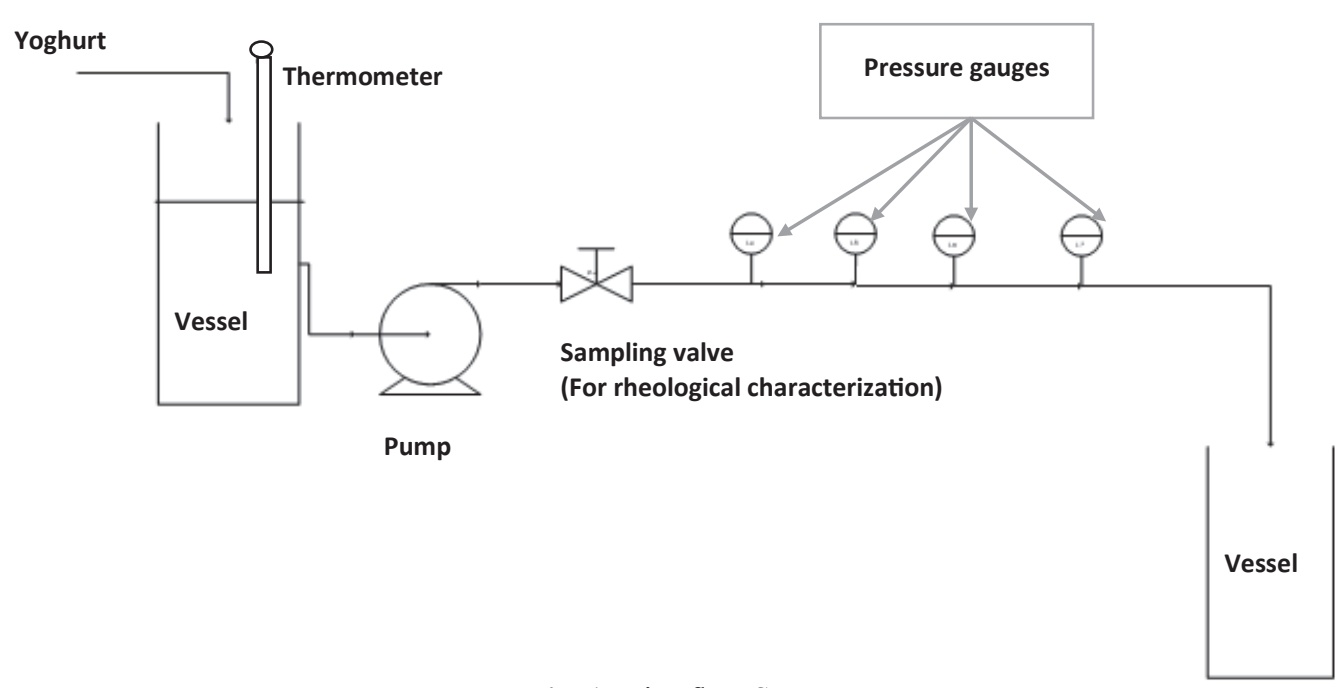

Fig. 1. Pipe flow Setup.

Rheological measurements The rheological measurements were performed at controlled temperature of $20.0 \pm$ $0.1^{\circ} \mathrm{C}$ using a controlled stress strain rheometer (PHYSICA, MCR 300, Paar Physica) with a cone and plate sample geometry ( $4^{\circ}$ cone, $40 \mathrm{~mm}$ diameter plate, $150 \mu \mathrm{m}$ truncation gap). Since the structure of yoghurt gel is sensitive to its shear deformation history, samples were carefully loaded to the rheometer. To diminish structural differences among samples caused by different treatments, this was followed by $300 \mathrm{~s}$ equilibration to allow for a structural rebuilding that would solely be dependent on the composition of the yoghurt.

The experiments performed to characterize the shear, and time dependency of the flow behaviour of stirred yoghurt consisted of a series of two measurements; firstly, the flow curves of yoghurt were measured by increasing (forward measurements) and decreasing (backward measurements) the shear rate. The shear rate was varied from 1 to $600 \mathrm{~s}^{-1}$ with changing rate of $12.2 \mathrm{~s}^{-1}$. Secondly, the shear stress was measured as a function of time at constant shear rate. Four different shear rates $\left(40,60,100\right.$, and $\left.140 \mathrm{~s}^{-1}\right)$ were applied to determine different rheological parameters at $20^{\circ} \mathrm{C}$. For each shear rate, $2000 \mathrm{~s}$ of shearing time were enough to reach the "plateau" state, which is the equilibrium state of the viscosity.

\section{Results and Discussion}

\section{Casein Content}

(1) Flow curves Figure 2 shows the flow curves ( $\tau$ vs $\gamma$ ) for stirred yoghurt of different casein contents. The shear stress - shear rate relationship was non-linear, indicating that yoghurt behaved as a non-Newtonian fluid at different casein concentration. In addition, the presence of hysteresis loops was an indication of the shearing effect on the molecular structure of stirred yoghurt, which means that the stirred yo- ghurt behaved as a thixotropic material. The hysteresis loop area may be assumed to be the difference between energies required for structural breakdown and rebuilding. In other words, all the data in Figure 2 shows that there was an irreversible, shear-induced and damage affecting of the molecular structure of yoghurt, namely fats and caseins. However, flow curves of yoghurts produced with high casein content had a higher slant angle and higher values of shear stress for the same value of shear rate, indicating that increasing the casein content in stirred yoghurt resulted in an increase in the apparent viscosity. These yoghurts with high casein content showed more resistant to action of shear forces. This can be attributed to the increased interparticle interactions in the yoghurt, mainly caused by self-aggregation of proteins. The results are in accord with that reported by Krzeminski et al. (2011), where they reported that the resistance towards shearinduced disruption of yoghurt gels increased with increasing proportion of casein protein in the protein mixture.

On the other hand, the presence of hysteresis loops, i.e., the difference existing between the forward and backward measurements, reveals that the stirred yoghurt would exhibit a thixotropic behaviour. Figure 2 also shows that an increase in the casein content caused an increase in hysteresis loop area of flow curves, which means an increase in the degree of thixotropy of the yoghurt. However, the effect of casein content on the structure breakdown of yoghurt cannot be quantified correctly using the hysteresis loop area, because this area will be changed based on the range of the shear rate.

(2) Time-dependent behaviour Fresh stirred yoghurt samples were sheared in the viscometer at different constant shear rates, namely; 40, 60, 100, and 140 1/s. The first value of shear rate is closely correlated to the sensorial perception in mouth of a product (Abu-Jdayil and Mohameed, 2002). Figures 3 and 4 show the typical behaviour of the apparent 


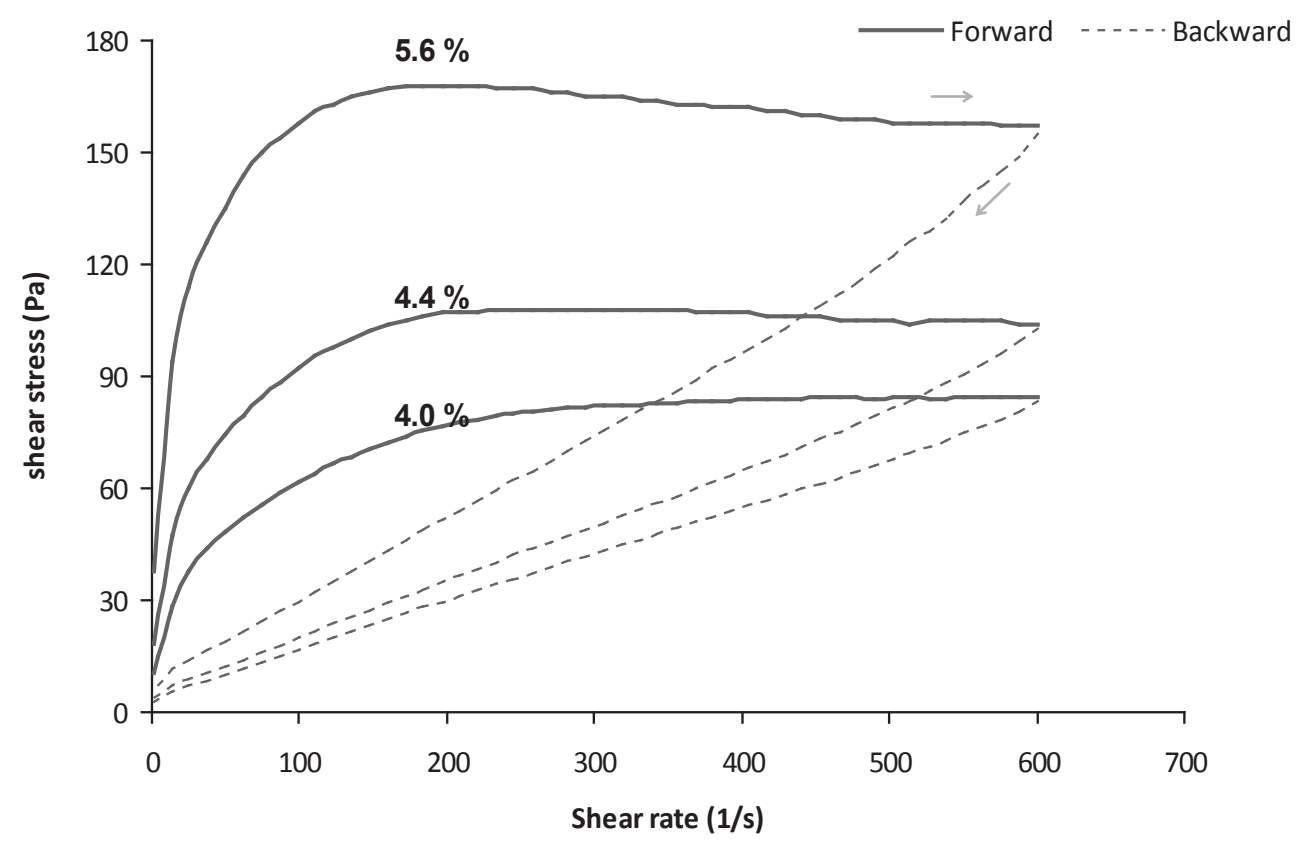

Fig. 2. Hysteresis loop of stirred yoghurt of different casein contents $(4.0,4.4$ and $5.6 \%(\mathrm{w} / \mathrm{w}))$ prepared using mixture of RR and ISt cultures.

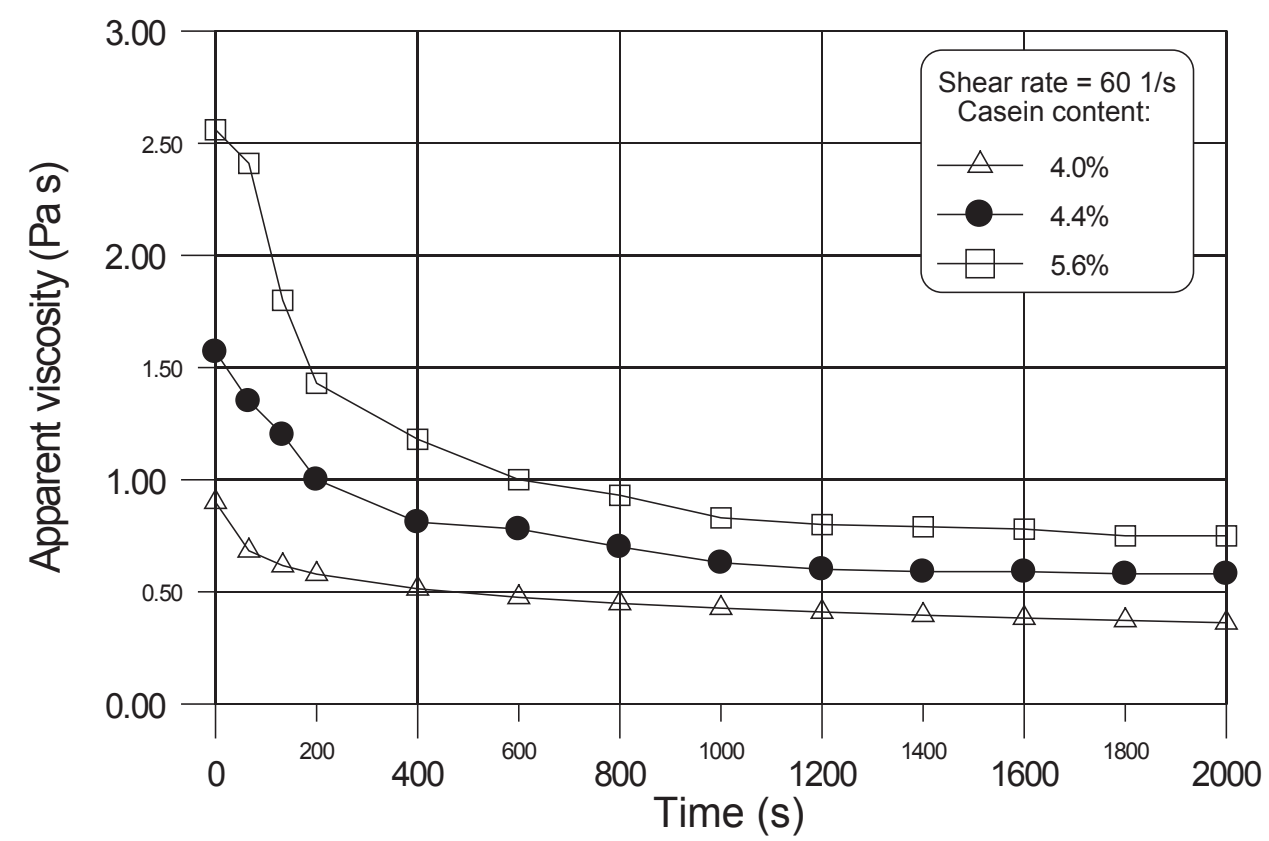

Fig. 3. Viscosity decay with time for different casein content at shear rate of $60 \mathrm{~s}^{-1}$ and $20^{\circ} \mathrm{C}$.

viscosity of stirred yogurt as a function of shearing time at different casein content and different shear rates, respectively. It is clear that the viscosity of yoghurt decreased with the shearing time to reach an equilibrium state within 2000 s. Yoghurts with high casein content were characterized by high viscosity values and strong dependence of apparent viscosity on shearing time. In other words, the degree of thixotropy in stirred yoghurts increased with the casein content. The yoghurt samples with the high casein content took more time to reach the equilibrium viscosity, since the protein network had to be disrupted first (Afonso and Maia, 1999).

From the obtained data at different shear rates, the initial and equilibrium power-law model parameters have been calculated. In addition, average values of the structural parameter $\left(\lambda_{e}\right)$, and the rate of structural decay $(C)$ for stirred yoghurt have been estimated at different levels of casein content. As shown in Table 1, the equilibrium flow behaviour index $\left(n_{e}\right)$ is less than the initial flow behaviour index $\left(n_{i}\right)$, 


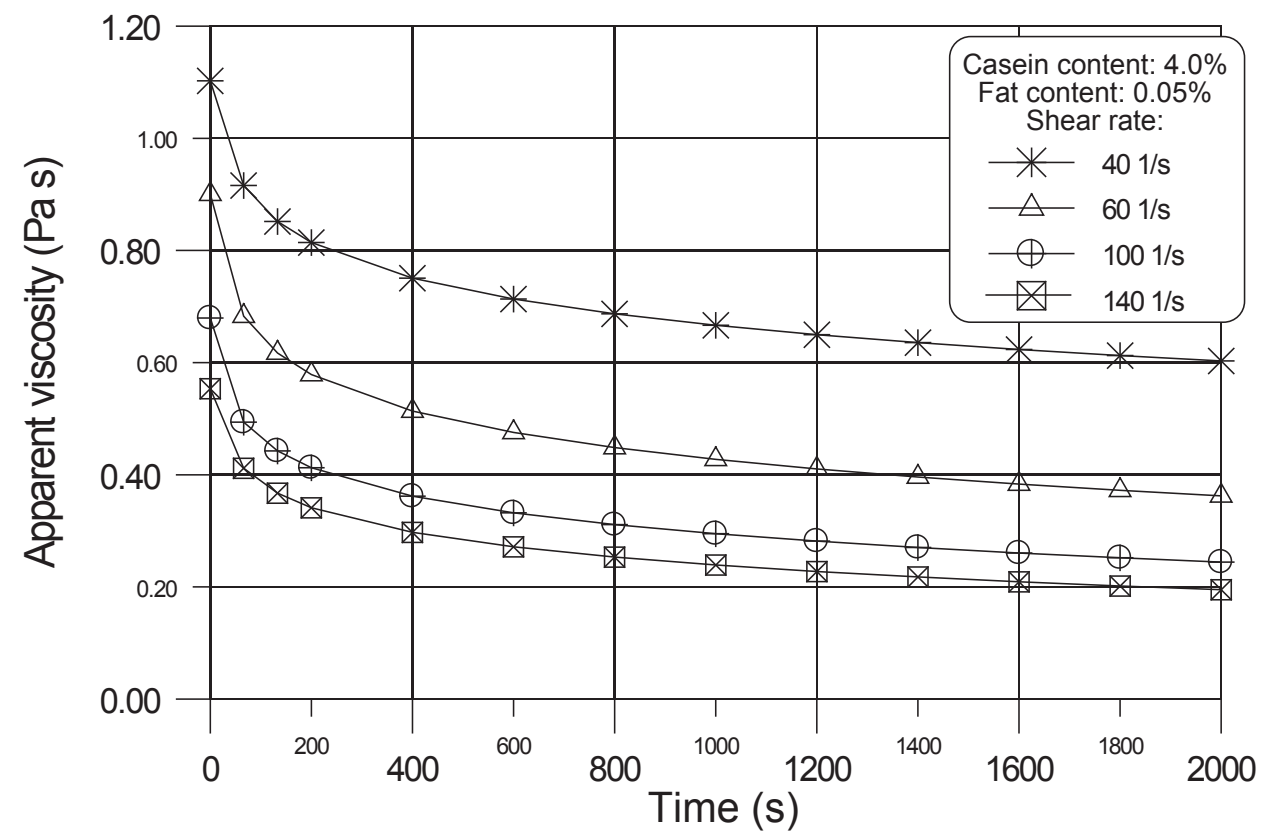

Fig. 4. Viscosity decay with time for different shear rates at $20^{\circ} \mathrm{C}$.

which means the yoghurt samples at equilibrium have more deviation from the Newtonian behaviour. Although the casein content had no clear effect on the flow behaviour index, it had strong effect on the consistency coefficients $(k)$, which represents the viscosity of yoghurt samples. Increasing the casein content led to an increase in the $\mathrm{k}$-values, this increase was more pronounced in the fresh yoghurt samples rather than in the sheared samples.

Table 1 shows also that increasing the casein content in yoghurt led to increase the rate of structure breakdown $(C)$ and to decrease the average value of the structural parameter $\left(\lambda_{e}\right)$, where $\frac{1}{\lambda_{e}}$ can be considered as a relative measure of the extent of thixotropy. Increasing the casein content in yoghurt has increased the number of cross-linking in the structure to produce gel with high apparent viscosity (see Figure 2), and the yoghurt became more structured and at the same time highly dependent on shearing conditions. Low values of $\lambda_{c}$ at high casein content means that the structure break down (percentage basis) is high with high casein content, in other words, the casein content increased the degree of thixotropy of the stirred yoghurt.

Table 2 shows the Reynolds number $(R e)$, structure number $(\mathrm{Se})$ and Modified Deborah number $(\mathrm{De})$ for different casein contents stirred yoghurts. During the flow in a pipe, the structure number has three cases; if the $S e$ is smaller than one, then the fluid structure will build up during the flow in the pipe. In other words, the build-up rate of the structure is higher than the breakdown rate. The second case is when the structure number $(\mathrm{Se})$ is greater than one; here the build-up

Table 1. The rheological properties of stirred yoghurt at different casein contents.

\begin{tabular}{ccccccc}
\hline Casein $\%(\mathrm{w} / \mathrm{w})$ & $n_{i}$ & $n_{e}$ & $k_{i}\left(\right.$ Pa.s $\left.^{n}\right)$ & $k_{e}\left(\right.$ Pa.s $\left.^{n}\right)$ & Average $\lambda_{e}$ & Average $C\left(\mathrm{~s}^{-1}\right)$ \\
\hline 4.0 & 0.32 & 0.24 & 14.9 & 7.5 & 0.460 & 0.006 \\
4.4 & 0.31 & 0.22 & 18.5 & 10.3 & 0.396 & 0.008 \\
5.6 & 0.35 & 0.25 & 34.0 & 15.7 & 0.297 & 0.013 \\
\hline
\end{tabular}

Table 2. Reynolds number, structure number, and modified Deborah number for different casein stirred yoghurt.

\begin{tabular}{ccccc}
\hline Casein $\%(\mathrm{w} / \mathrm{w})$ & $\begin{array}{c}\text { Reynolds Number } \\
(\mathrm{Re})\end{array}$ & $\begin{array}{c}\text { Measured Structure } \\
\text { Number }(\mathrm{Se})\end{array}$ & $\begin{array}{c}\text { Calculated Structure } \\
\text { Number }(\mathrm{Se})\end{array}$ & $\begin{array}{c}\text { Modified Deborah } \\
\text { Number }(\mathrm{De})\end{array}$ \\
\hline 4.0 & 8.3 & 2.32 & 2.2 & 16.52 \\
4.4 & 6.6 & 2.59 & 2.4 & 69.4 \\
5.6 & 4.4 & 4.5 & 3.3 & 72.1 \\
\hline
\end{tabular}


rate of the structure is slower than the breakdown rate. This means that during the flow in pipe a breakdown of the fluid structure will occur. When $S e=1$, the fluid structure at the pipe entrance is equal to the mean value of the equilibrium structure at the end of the pipe, which means there is no build-up or breakdown of structure.

The structure number $(\mathrm{Se})$ for stirred yoghurt has been calculated using the measured rheological parameters (Equation 5) and compared with that measured by measuring the pressured drops along the pipe.

In the present case the values of $\mathrm{Se}$ (measured or calculated) were always greater than 1 (see Table 2). This means that stirred yoghurt structure breakdown occurs through the circular pipe and it is function of the casein content. In all cases, the structure of the yoghurt gel cannot be rebuilt again and the breakdown rate increases as the casein content increases. In addition, the difference between the calculated and measured $S e$ was acceptable, especially at low casein content. The results support the validity of the approximate expression (Equation 5) to estimate the structural number or to calculate the pressure drop of the stirred yoghurt through a circular pipe.

Modified Deborah number De is the ratio of the relaxation time characterizing the time it takes for a fluid to adjust to applied stresses or deformations, and the minimum residence time of the fluid in the pipe. It incorporates both on the elasticity and viscosity of the material. The smaller the Deborah number, the material behaves more fluid like with an associated Newtonian viscous flow. At higher Deborah numbers, the material behaviour changes to non-Newtonian regime, increasingly dominated by elasticity, reaching solid like behaviour with very high Deborah numbers (Reiner, 1964). As can be seen in Table 2, increasing the casein content in stirred yoghurt increased the Deborah number, which means that the presence of casein increased the elasticity of the yoghurt, which is a characteristic of a gel structure.

\section{Fat Content}

(1) Flow curves Milk and cream are examples of fatin-water emulsions. The milk fat exists as small globules or droplets dispersed in the milk serum. Their diameters range from 0.1 to $20 \mathrm{~m}$. Milk fat is liquid when milk leaves the udder at $37^{\circ} \mathrm{C}$. This means that the fat globules can easily change their shape when exposed to moderate mechanical treatment - pumping and flowing in pipes for instance without being released from their membranes.

Four stirred yoghurt samples with different fat contents $(0.05,1,3$, and $8 \%(\mathrm{w} / \mathrm{w}))$ were pumped through a circular pipe with a flow rate of $3.6 \mathrm{~L} / \mathrm{min}$ at $20^{\circ} \mathrm{C}$ and subjected to the rheological tests. Figure 5 shows the flow curves of these samples measured under the forward and backward conditions. Increasing the fat content resulted in a rise of shear stress and apparent viscosity of the stirred yoghurt. An addition of fat resulted in an overall increased compactness of the gel yoghurt microstructure (Krzeminski et al., 2011). Shaker et al. (2000) found that the increase in fat content of plain yoghurt led to an increase in viscosity. In addition, the

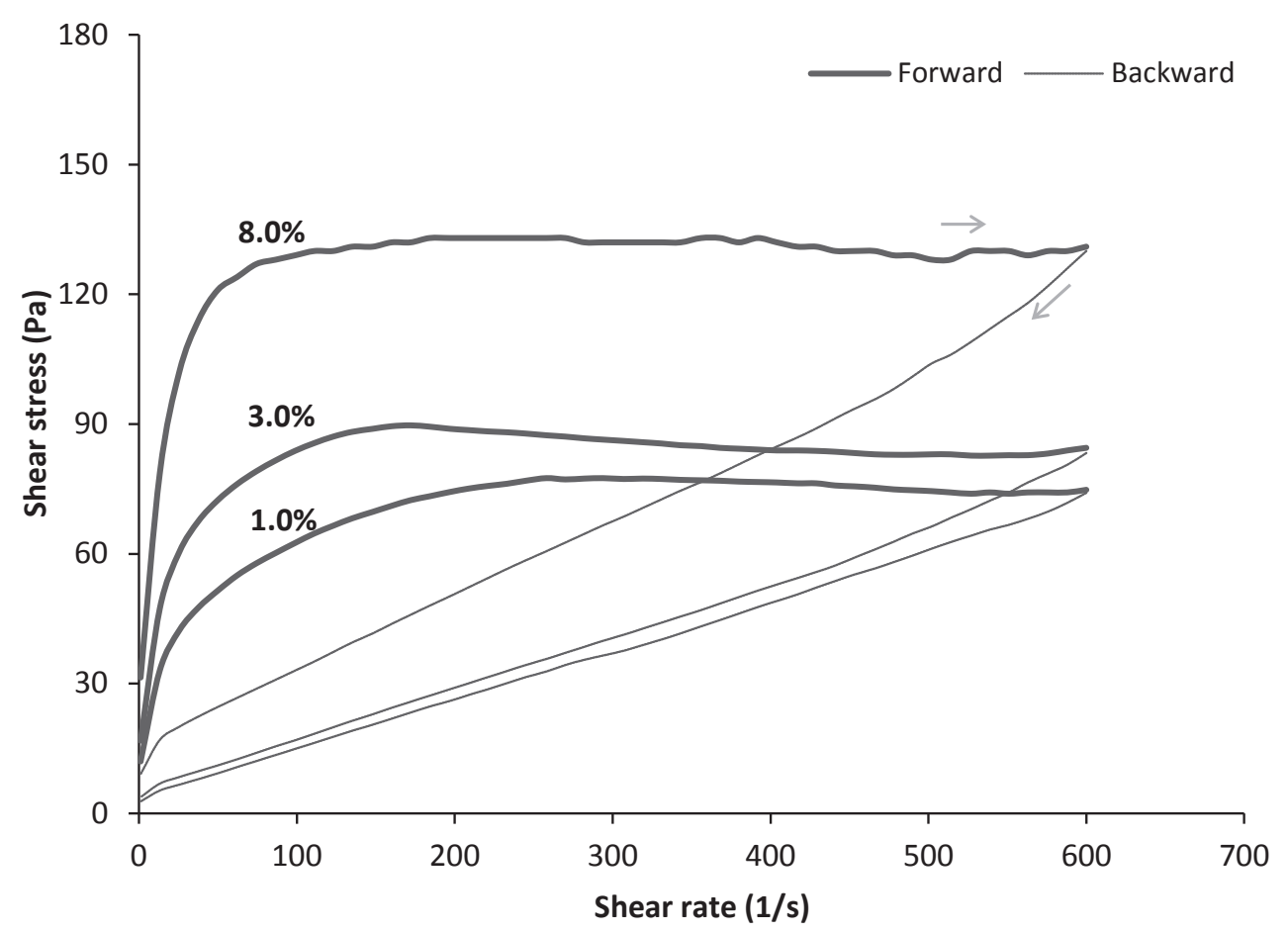

Fig. 5. Hysteresis loop of stirred yoghurt of different fat contents $(1.0,3.0$ and $8.0 \%(\mathrm{w} / \mathrm{w}))$ prepared using mixture of RR and ISt cultures. 
increase in the fat content led to increase the degree of thixotropy of the stirred yoghurt. This can be revealed from the increase in the area of hysteresis loops based on the increase in the fat content. However, the subsequent results will clarify more the effect of fat on the structure breakdown of stirred yoghurt.

(2) Time-dependent behaviour The effect of fat content on the rheological time-dependent behaviour of stirred yoghurt was investigated by shearing fresh samples in the viscometer at constant different shear rates for $2000 \mathrm{~s}$. The decay of yoghurt viscosity with shearing time as a function of the fat content is illustrated in Figure 6. It is clear that the dependence of apparent viscosity on the shearing time increased with fat content, where the thixotropic behaviour was more pronounced at high fat content. The apparent viscosity of the sample with highest fat content took more time to reach equilibrium, since the fat globules which were acting as linking protein agents had to be disrupted first (Krzeminski et al., 2011).

By collecting the rheological data (apparent viscosity versus shearing time) at different shear rates, the power-law model parameters, average values of the structural parameter $\left(\lambda_{e}\right)$, and the rate of structural decay $(C)$ for stirred yoghurt have been calculated at different levels of fat content. Table 3 shows that the equilibrium flow behaviour index $\left(n_{e}\right)$ is less than the initial flow behaviour index $\left(n_{i}\right)$, which means the yoghurt samples at equilibrium have more deviation from the Newtonian behaviour. This behaviour was more significant in samples with high fat content. In addition, the fat content has a clear effect on the consistency coefficients $(k)$, which represents the viscosity of yoghurt samples. Increasing the fat level in stirred yoghurt led to an increase in the $k$-values for both fresh and sheared samples.

In addition, Table 3 shows that the increase in the fat content of stirred yoghurt led to increase the rate of structure breakdown $(C)$ and to decrease the average value of the structural parameter $\left(\lambda_{e}\right)$, which support the flow curves results that increasing the fat content increased the degree of thixotropy of stirred yoghurt.

On the other hand, the Reynolds number $(R e)$, structure number $(S e)$ and modified Deborah number $(D e)$ are reported in Table 4 for stirred yoghurt with different fat contents. Al-

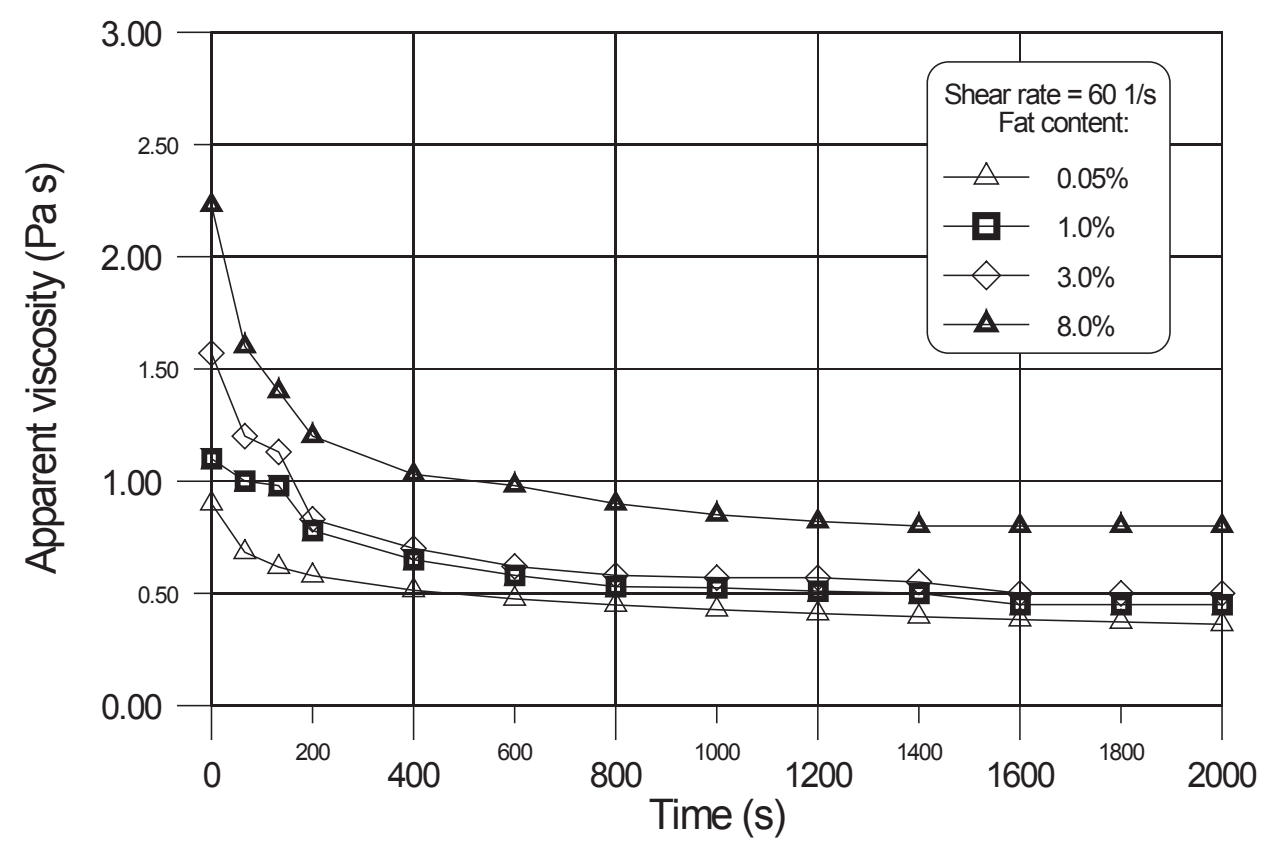

Fig. 6. Viscosity decay with time for different fat content at shear rate of $60 \mathrm{~s}^{-1}$ and $20^{\circ} \mathrm{C}$.

Table 3. The rheological properties of stirred yoghurt at different fat contents.

\begin{tabular}{ccccccc}
\hline Fat $\%(\mathrm{w} / \mathrm{w})$ & $n_{i}$ & $n_{e}$ & $k_{i}\left(\right.$ Pa.s $\left.{ }^{n}\right)$ & $k_{e}\left(\right.$ Pa.s $\left.s^{n}\right)$ & Average $\lambda_{e}$ & Average $C\left(\mathrm{~s}^{-1}\right)$ \\
\hline 0.05 & 0.320 & 0.240 & 14.9 & 7.5 & 0.46 & 0.006 \\
1.00 & 0.238 & 0.212 & 20.5 & 10.3 & 0.45 & 0.007 \\
3.00 & 0.297 & 0.199 & 24.5 & 13.1 & 0.32 & 0.142 \\
8.00 & 0.436 & 0.228 & 22.2 & 18.4 & 0.27 & 0.160 \\
\hline
\end{tabular}


Table 4. Reynolds number, structure number, and modified Deborah number for different fat stirred yoghurt.

\begin{tabular}{ccccc}
\hline Fat \%(w/w) & $\begin{array}{c}\text { Reynolds Number } \\
(\mathrm{Re})\end{array}$ & $\begin{array}{c}\text { Measured Structure } \\
\text { Number }(\mathrm{Se})\end{array}$ & $\begin{array}{c}\text { Calculated Structure } \\
\text { Number }(\mathrm{Se})\end{array}$ & $\begin{array}{c}\text { Modified Deborah } \\
\text { Number }(\mathrm{De})\end{array}$ \\
\hline 0.05 & 8.3 & 2.32 & 2.23 & 16.52 \\
1.00 & 7.4 & 2.42 & 2.69 & 23.92 \\
3.00 & 6.2 & 2.57 & 3.05 & 31.30 \\
8.00 & 3.9 & 2.83 & 3.95 & 52.50 \\
\hline
\end{tabular}

though there were some differences between measured and calculated structure numbers $(\mathrm{Se})$, both were greater than unity, and increased with the fat content. This yields that stirred yoghurt structure breakdown occurred during the flow in the circular pipe and its rate increased with increasing fat content. It is likely that the shearing of fats during the flow in the circular pipe causes disruption of the three-dimensional structure through the breaking of the primary and secondary bonds in the fat structure (Abu-Jdayil et al., 2004). On the other hand, Table 4 shows that increasing the fat content in stirred yoghurt, increased the Deborah number, which means the presence of fat increased the elasticity of the yoghurt, where the three dimensional fat polymers contribute in the increase of the gel strength of stirred yoghurt. In addition, the data presented in Table 2 and 4, reveal that the contribution of casein in the elasticity of stirred yoghurt was greater than that of fat, since the Deborah number in the cases of casein is greater, which is common in stirred yoghurt (Ciron et al., 2012).

\section{Conclusions}

The structure breakdown of the stirred yoghurt in a circular pipe was evaluated from the rheological measurements and compared with that estimated from flow mode data through estimating the dimensionless structure number $(\mathrm{Se})$ and Deborah number $(D e)$. The results proved that the simple rheological tests can be used to estimate the behaviour of stirred yoghurt in pipe flow. In addition, the results showed that the stirred yoghurt samples with high casein and/or fat content produced gel with high apparent viscosity, and the yoghurt became more structured and at the same time highly dependent on shearing conditions. The rheological and pipe flow tests revealed that the thixotropic behaviour of stirred yoghurt was more pronounced at high casein and fat content, where the rate of structure breakdown of yoghurt in pipe flow is greater than the build-up rate. On the other hand, the stirred yoghurt with high casein and fat content exhibited high value of Deborah number $(D e)$, which means an increase in the elasticity of the yoghurt. However, the results revealed that the contribution of casein in the elasticity of stirred yoghurt was greater than that of fat.
Acknowledgment Authors would like to acknowledge the support and advices of Dr. Alec. E. James (School of Chemical Engineering and Analytical Science, University of Manchester).

\section{References}

Abu-Jdayil, B. and Mohameed, H. (2002). Experimental and Modelling Studies of the Flow Properties of Concentrated Yogurt as Affected by the Storage Time. Journal of Food Engineering, 52, 359-365.

Abu-Jdayil, B. (2003). Modelling the time-dependent rheological behaviour of semi-solid foodstuffs. Journal of Food Engineering, 57, 97-102.

Abu-Jdayil, B., Mohameed, H. and Eassa, A. (2004). Rheology of Wheat Starch-Milk-Sugar Systems: Effect of Starch Concentration, Sugar Type and Concentration, and Milk Fat Content, Journal of Food Engineering, 64, 207-212.

Abu-Jdayil, B., Shaker, R.R. and Jumah, R.Y. (2000). Rheological Behavior of Concentrated Yogurt (Labneh). International Journal of Food Properties, 3, 207-213.

Afonso, I.M. and Maia, J.M. (2000). Rheological monitoring of structure development and re-bodying of set-style yoghurt. Applied Rheology, 10, 73-79.

Akalin, A.S., Unal, G., Gonc, S. and Fenderya, S. (2008). Effects of whey protein concentrate and fructooligosaccharide on the rheological and sensory properties of reduced-fat probiotic yoghurt. Milchwissenschaft, 63, 171-174.

Aportela-Palacios, A., Sosa-Morales, M.E. and Vélez-Ruiz, J.F. (2005). Rheological and physicochemical behaviour of fortified yoghurt, with fibre and calcium. Journal of Texture Studies, 36, 333-349.

Benzech, T. and Maingonnat, J.F. (1993). Flow Properties of Stirred yoghurt: Structural parameter approach describing timedependency. Journal of Texture Studies, 24, 445-473.

Ciron, Ch.I.E., Gee, V.L., Kelly, A.L. and Auty, M.A.E. (2011). Effect of microfluidization of heat-treated milk on rheology and sensory properties of reduced fat yoghurt. Food Hydrocolloids, 25, 1470-1476.

Ciron, Ch.I.E., Gee, V.L., Kelly, A.L. and Auty, M.A.E. (2012). Modifying the microstructure of low-fat yoghurt by microfluidisation of milk at different pressures to enhance rheological and sensory properties. Food Chemistry, 130, 510-519. 
Damin, M.R., Alcantara, M.R., Nunes, A.P. and Oliveira, M.N. (2009). Effects of milk supplementation with skim milk powder, whey protein concentrate and sodium caseinate on acidification kinetics, rheological properties and structure of non-fat stirred yogurt. LWT-Food Science and Technology, 42, 1744-1750.

Damin, M.R., Minowa, E., Alcantara, M.R. and Oliveira, M.N. (2008). Effect of cold storage on culture viability and some rheological properties of fermented milk prepared with yogurt and probiotic bacteria. Journal of Texture Studies, 39, 40-55.

Everett, D.W. and McLeod, R.E. (2005). Interactions of polysaccharide stabilisers with casein aggregates in stirred skim-milk yoghurt. International Dairy Journal, 15, 1175-1183

Fangary, Y.S. Barigou, M. and Seville, J.P.K. (1999). Simulation of yoghurt flow and prediction of its end-of-process properties using rheological measurements. Transactions of the Institution of Chemical Engineers, Part C, 77, 33-39.

Gost, B. (1995). "Dairy Handbook process", Tetra park processing Sweden.

Jumah, R.Y., Abu-Jdayil, B. and Shaker, R.R. (2001). Effect of Type and Level of Starter Culture on the Rheological Properties of Set Yogurt During Gelation Process. International Journal of Food Properties, 4, 531-544.

Kemblowski, Z. and Petera, J. (1981). Memory effect during the flow of thixotropic fluids in pipes. Rheologia Acta, 20, 311-323.

Krzeminski, A., Großhable, K. and Hinrichs, J. (2011). Structural properties of stirred yoghurt as influenced by whey proteins. Food Science and Technology, 44, 2134-2140

Kücükcetin, A. (2008). Effect of heat treatment and casein to whey protein ratio of skim milk on graininess and roughness of stirred yoghurt. Food Research International, 41, 165-171.

Lee, W.J. and Lucey, J.A. (2004). Structure and physical properties of yoghurt gels: Effect of inoculation rate and incubation temperature. Journal of Dairy Science, 87, 3153-3164.

McCann, T.H., Fabre, F. and Day, L. (2011). Microstructure, rheology and storage stability of low-fat yoghurt structured by carrot cell wall particles. Food Research International, 44, 884-892
Mohameed, H., Abu-Jdayil, B. and Al-Shawabkeh, A. (2004). Effect of solids concentration on the rheology of Labneh (concentrated yogurt) produced from sheep milk. Journal of Food Engineering, 61, 347-352.

Pipkin, A.C. (1986). Lectures on viscoelasticity theory, 2nd edn. Springer, New York, USA.

Puvanenthiran, A., Williams, R.P.W. and Augustin, M.A. (2002). Structure and viscoelastic properties of set yoghurt with altered casein to whey protein ratios. International Dairy Journal, 12, 383-391.

Rao, P.G. (2010). Fundamentals of Food Engineering, PHI Learning Pvt Ltd, New Delhi.

Reiner, M. (1964). The Deborah Number. PHYSICS TODAY, January, 62 .

Renan, M., Guyomar F., Arnould-Delest, V., Pâquet, D., Brulé, G. and Famelart, M.H. (2009). Rheological properties of stirred yoghurts as affected by gel $\mathrm{pH}$ on stirring, storage temperature and $\mathrm{pH}$ changes after stirring. International Dairy Journal, 19, 142148.

Schmitt, L., Ghnassia, G., Bimbenet, J.J. and Cuvelier, G. (1998). Flow Properties of stirred yoghurt: Calculation of the pressure drop for a thixotropic fluid. Journal of Food Engineering, 37, 367-388.

Shaker, R.R., Abu-Jdayil, B., Jumah, R.Y. and Ibrahim, S. (2002). Rheological Properties of Set Yogurt as Influenced by Incubation temperature and Homogenization. Journal of Food Quality, 25, 409-418.

Sodini, I., Remeuf, F., Haddad, S., and Corrieu, G. (2004). The relative effect of milk base, and process on yogurt texture: a review. Critical Reviews in Food Science and Nutrition, 44, 113-137.

Steffe, J.F. (1996). Rheological Methods in Food Process Engineering, Second Edition, Freeman Press, MI, USA.

Xu, Z.M., Emmanouelidou, D.G., Raphaelides, S.N. and Antoniou, K.D. (2008). Effects of heating temperature and fat content on the structure development of set yogurt. Journal of Food Engineering, 85, 590-597. 